\section{NARRATIVAS PROCESSUAIS SOBRE VIOLENCIA NO TRABALHO BANCÁRIO: UMA ABORDAGEM SÓCIOCONSTRUCIONISTA}

\author{
Procedural Narratives about Violence in Banking Work: A \\ Social Constructionist Approach
}

\author{
Narrativas Procesales sobre la Violencia en el Trabajo en \\ Bancos: UnEnfoque Construccionista Social
}

\author{
Récits de ProcédureConcernant la Violence de Travaildans le \\ SecteurBancaire: Une Approche Socio-Constructiviste
}

Artigo Original
Com este artigo tem-se por objetivo analisar como os diferentes atores envolvidos em um processo tramitado no âmbito da justiça do trabalho interpretam os sentidos atribuídos à violência. Para tanto, optou-se pela abordagem teórico-metodológica sócioconstrucionista e tomaram-se como objeto de análise as narrativas processuais registradas pelo processo trabalhista em foco. Para fins deste trabalho, considerou-se como atores do processo a trabalhadora (reclamante nominada de modo fictício de Maria) e seu advogado de defesa, o juiz do trabalho que julgava o processo e o advogado que representava os interesses do Banco $\mathrm{H}$, considerado no processo como reclamado. O protocolo de análise das narrativas contidas no processo seguiu o seguinte percurso metodológico: descrição sintética das especificidades do processo trabalhista, destacando as experiências de violência vividas pela reclamante; seleção de extratos das narrativas que expressavam as "vozes" e interpretações dos atores envolvidos no processo, sobre os atos de violência retratados pelo processo trabalhista; e agrupamento das narrativas registradas no processo em três categorias que abrigam as produções discursivas dos atores, ou seja, Acusação, Defesa e Juiz do trabalho. Finalmente, foram identificadas diferentes subcategorias que pudessem revelar os sentidos da violência sob a ótica dos atores acima mencionados. A releitura e análise das práticas discursivas registradas pelo processo evidenciaram que Maria vivenciou, ao longo de sete anos de trabalho em uma organização bancária, diversos eventos cotidianos que foram reconhecidos pela justiça do trabalho como atos de violência. As análises das práticas discursivas registradas no processo judicial em foco revelaram que os atos de violência vivenciados por Maria foram interpretados de modo diferente pelos diferentes atores envolvidos. A interpretação e compreensão desses diferentes sentidos sinalizam que, dependendo dos interesses e do processo de subjetivação em jogo, a violência pode ser naturalizada, banalizada, repudiada e até mesmo admitida no contexto do trabalho.

Palavras-chave: violência; trabalho bancário; sofrimento no trabalho; construcionismo social; análise de narrativas.

Abstract

The objective of this article is to analyze how different actors involved in a Labor JudicialProcess, which took place at a Labor Justice Court interpret meanings attributed to violence at work. The social constructionist theoretical-methodological approach was chosenin order to reach this objective, and the objects of analysis were the processual
Recebido em: 08/07/2013

Revisado em: 15/06/2015

Aceito em: 22/06/2015 
narratives recorded during the labor judicial process in focus. For the purposes of this study, the actors of the process were the worker (the complainant, fictitiously named Maria) and her defense attorney; the judge; and the lawyer who represented the interests of the Bank $H$, considered the claimed in the process. The protocol for analyzing the narratives contained in the judicial process followed the subsequentmethodological route: (1) a short description of the specifics of the labor judicialprocess, highlighting the complainant experiences of violence; (2) the selection of extracts from the narratives that expressed the "voices " and interpretations of the actors involved in the judicialprocess about the violence depictedin the process; and (3)the grouping of narrative extracts recorded in the judicialprocess into three categories that contained the discursive production of the three different actors, i.e. Prosecution, Defense and Judge. Finally, different subcategories were devised in order to reveal the violence meanings from the perspective of the aforementioned actors. The retelling and analysis of the discourse practices recorded during the judicial process showed that Maria experienced many everyday events, recognized by the labor justice court as acts of violence,during more than seven years of work in the bank organization. The analysis of the discoursepractices recorded in the judicial process in focus also showthat the discourse practices revealed that the violence experienced by Maria were interpreted differently by the different actors involved. The interpretation and understanding of these different meanings indicate that, depending on the interests and the subjectivation process in play, violence can be naturalized, trivialized,rejected, and even admitted in work.

Keywords: violence; bank work; suffering at work; social constructionism; narrative analysis.

\section{Resumen}

Con este artículo se objetivó analizar cómo los diferentes actores involucrados en un marco de justicia llevados ante el proceso de trabajo interpretan los significados atribuidos a la violencia. Para ello se optó por el enfoque teórico-metodológico construccionista social y fue tomado como objeto de análisis las narrativas procesales registradas durente el proceso de trabajo en el enfoque. Para efectos de este estudio, se consideró como actores en el proceso de trabajo la trabajadora (llamadade denunciante, ficticiamente María) y su abogado defensor, el juez del proceso de trabajo y el abogado que representaba a los intereses del Banco H, considerado en el proceso como el denunciado. El protocolo metodológico de análisis de los relatos contenidos en el proceso siguió la siguiente ruta: breve descripción de los detalles del proceso de trabajo, destacando las experiencias de violencia experimentada por la demandante, la selección de los extractos de las narrativas que expresavan las "voces" y las interpretaciones de los actores involucrados en el proceso acerca de la violencia retratada por el proceso de trabajo, y la agrupación de las narraciones grabadas en el proceso en tres categorías que albergan la producción discursiva de los actores, es decir, la Denunciante, la Defensa y el Juez. Por último, se identificaron diferentes subcategorías que podrían revelar los significados de la violencia desde la perspectiva de los actores antes mencionados. El recuento y análisis de las prácticas discursivas registrados por el proceso mostraron que María experimentó durante más de siete años de trabajo en una entidad bancaria, muchos acontecimientos cotidianos que fueron reconocidos por el tribunal laboral como actos de violencia. El análisis de las prácticas discursivas registradas en el proceso judicial en atención reveló que la violencia experimentada por María fue interpretada de maneras diferentes por los diferentes actores involucrados en el proceso. La interpretación y la comprensión de estos diferentes sentidos indican que, en función de los intereses y del proceso desubjetivación puestos en juego, la violencia puede ser naturalizada, trivializada, rejitada y ate mismo admitida en el trabajo.

Palabras clave: violencia; trabajo bancario; sufrimiento en el trabajo; construccionismo social; análisis narrativo.

\section{Résumé}

Avec cet article a été d'analyser comment les différents acteurs impliqués dans un cadre de justice portées devant le processus de travail interpréter les significations attribuées à la violence. Pour ce faire, nous avons opté pour l'approche théorique et méthodologique socio-constructiviste et a été considérée comme l'objet de récits de procédure d'analyse enregistrés par le processus de travail mis au point. Aux fins de cette étude, il a été considéré comme des acteurs dans le processus de travail (appelé le plaignant fictivement Marie) et son avocat de la défense, le juge a estimé que le processus de travail et l'avocat qui représentait les intérêts de la Banque $H$, considéré dans le processus selon. L'analyse de protocole des récitscontenusdans le processus méthodologique suivil'itinérairesuivant: brève description des détails du processus de travail, en soulignant les expériences de la violencesubie par le requérant, la sélectiond'extraits des récits qui expriment les «voix» et les interprétations des acteur simpliqués dans le processus sur la violence dépeinte par le processus de travail, et le regroupement des récitsen registrés dans le processus en trois catégoriesqui abritent la production discursive des acteurs, à savoir l'Accusation, la Défense et la Justicetravail. Enfin, différentessous-catégoriesqui pour raientrévéler la signification de la violence du point de vue des acteurs mentionnés ci-dessusontété identifiés. Le récit et l'analyse des pratiques discursivesen registrés par le processusont montré que Marie a connu plus de sept années de travaildans un organisme bancaire, de nombreux événementsquoti diensquiontétére connus par les tribunaux du travail que les actes de violence. L'analyse des pratiques discursivesen registrés dans le processus judiciaire au point a révélé que la violence subie par Maria ontété interprétés différemment par les différentes parties prenantes. L'interprétation et la compréhension de ces différents sensindiquent que, en fonction des intérêts et de la subjectivité dans le processus de jeu, 
la violence peutêtre naturalisé, banalisée, divorcée et a mêmead mis dans le travail.

Mots-clés: la violence; le travail de la banque; la souffranceautravail; constructivisme social; l'analysenarrative.

As intensas transformações culturais, políticas e econômicas pelas quais passam as sociedades atuais, geram novas perspectivas de funcionamento das organizações inseridas nesse contexto (Almeida; Melo; Brito, 2006).

As transformações dos modos de gestão do trabalho podem acabar favorecendo situações de violência ou constituem em si mesmas a violência, quando comprometem a integridade do trabalhador em aspectos físicos, sociais, emocionais e morais, transformando negativamente o ambiente de trabalho (Guimarães, 2009; Pereira; Brito; Carrieri; Lima; Cappelle, 2008; Rosenfield, 2004).

Essa concepção do fenômeno violência revela a natureza mutante e suas múltiplas formas de manifestação em momentos, locais e circunstâncias distintas. Essas particularidades da violência dificultam a sua diagnose e intervenção, obscurecendo os efeitos de um problema que afeta milhões de trabalhadores em todo o mundo. Tratase de um fenômeno socialmente construído que pode ser naturalizado e até mesmo admitido no contexto do trabalho e das organizações. Assim sendo, agentes e vítimas da violência mascaram, legitimam e negam a sua existência. Consequentemente, milhares de trabalhadores acabam optando pelo silêncio e aceitação de relações de trabalho marcadas por diferentes formas de agressividade e violência que não são denunciadas, contabilizadas pelas estatísticas oficiais.

Nesse cenário, destaca-se o setor bancário brasileiro, que passou por uma reestruturação produtiva a partir da década de 1960, a qual precarizou o trabalho e sujeitou os bancários às praticas de controle e dominação expressas de várias formas, como violência. Essas formas de manifestação de violência no ambiente organizacional bancário, imerso no processo de reestruturação produtiva, podem ser investigadas, entre outras dimensões, por meio dos sentidos produzidos.

Com este trabalho, objetivou-se desvendar os sentidos da violência no trabalho bancário sob a ótica dos múltiplos atores envolvidos no processo trabalhista transitado e julgado pela justiça do trabalho. Mais especificamente, pretende-se: a) apresentar relato do caso estudado de modo a particularizar e tipificar as diferentes formas de manifestação da violência no trabalho; b) interpretar os sentidos atribuídos à violência no trabalho pelos diferentes atores envolvidos no processo trabalhista, objeto de análise deste trabalho.

\section{Ideologia Gerencialista e Sofrimento no Trabalho Bancário}

A lógica financeira assume hoje o comando da economia e das organizações, abalando os modos de organização e gerenciamento. A gestão passa a ter caráter ideológico, constituindo-se, de acordo com Gaulejac (2007, p. 65), em um "sistema de pensamento que se apresenta como racional, ao passo que mantém uma ilusão e dissimula um projeto de dominação". Associada a valores como o empreendedorismo, o mérito e a qualidade, a ideologia gerencialista suscita, à primeira vista, adesão e consenso. No entanto, estes valores não constituem instrumentos de melhoria das condições de produção, mas sim de pressão, a fim de reforçar a produtividade e rentabilidade da empresa (Gaulejac, 2007).

Ao transformar o indivíduo em capital humano e gerar exclusão por meio da cultura do desempenho, a ideologia gerencialista banaliza a violência e naturaliza as degradações das condições de trabalho e o desenvolvimento da precariedade (Gaulejac, 2007). Estas e outras questões preocupantes rondam a questão do sofrimento no trabalho. Siqueira (2009) explica que a cultura organizacional predominante, caracterizada pela busca incessante por sucesso, gera sérios problemas de saúde, física e psicológica ao indivíduo. A relação que o trabalhador mantém com o mundo do trabalho pode levá-lo, além do trabalho excessivo, a uma desestruturação psicológica e emocional, tendo como consequências o estresse, a ansiedade, o uso de álcool e drogas. Apesar do fato de que as pessoas estão cada vez mais doentes, a organização preocupa-se com a saúde de seus empregados apenas no campo discursivo e nas formalidades funcionais (planos de saúde e direito a licenças). No entanto, não há uma discussão de seu papel enquanto causadora ou preconizadora desses problemas (Siqueira, 2009). Considerando o trabalho como o fator que cada vez mais influencia nesse processo de debilidade do indivíduo, "igualmente preocupante é a tolerância ao sofrimento subjetivo, aceitando-se a psiquiatrização do problema, tomado como algo normal, um dado da realidade que pode bem ser fruto da debilidade do indivíduo e não da pressão do contexto" (Salimon; Siqueira, 2013, p. 650).

As instituições bancárias brasileiras têm sido tema de muitas publicações sobre o sofrimento psíquico e a manifestação de diversas formas de violência nas políticas e práticas de gestão de pessoas (Bessi, 2009; Ferreira, 2007; Finazzi; Siqueira; Mendes, 2010; Grisci; 2008; Maciel; Cavalcante; Matos; Rodrigues, 2007; Oltramari, Grisci,\&Weber, 2011).

Embora o desgaste físico e mental provocado pelas atividades da categoria dos trabalhadores bancários não seja um fenômeno novo, a execução das tarefas tem exigido, cada vez mais, grande esforço cognitivo (atenção, 
responsabilidade), físico (esforços repetitivos, posturas estáticas) e raciocínio rápido no processo de tomada de decisão e avaliação dos riscos. Além de cargas excessivas de trabalho, os bancários executam suas atividades sob forte pressão, em um ritmo acelerado e eliminando pausas (diminuição de pessoal, aumento de volume de trabalho e público a ser atendido, cumprimento de prazos e metas na maioria das vezes inatingíveis) (Amazarray, 2011).

Para Grisci e Bessi (2004), o cotidiano dos bancários passou a ter caráter de transitoriedade, uma vez que se tornaram sujeitos de respostas rápidas e em constante insegurança quanto à sua permanência no emprego, em função da reestruturação produtiva aliada à adoção de novas tecnologias. As autoras apontam a precarização e intensificação do trabalho, o sofrimento psíquico e o adoecimento dos trabalhadores como algumas das consequências dessa reestruturação.

O contexto do trabalho bancário contemporâneo apresentado constitui-se um cenário propício à ocorrência de diversas formas de violência, inclusive simbólica, uma das formas pela qual a violência pode se expressar no espaço organizacional atual.

\section{Violência nas Relações de Trabalho}

O tema violência tem sido investigado para estudar diferentes contextos, sob enfoques distintos, em diversas áreas do conhecimento. Considerado fenômeno polissêmico e multicausal, configura-se um objeto híbrido, apresentando legítima pluralidade de abordagens - o que dificulta a elaboração de uma definição única que englobe o fenômeno como um todo, demandando estudos multifocais, transdisciplinares e intersetoriais.

Ao considerar a violência como um dos diferentes riscos a saúde individual e coletiva, a Organização Mundial da Saúde (OMS), em seu relatório sobre a temática (Krug; Dahlberg; Mercy; Zwi; Lozano, 2002, p. 5), define violência como "uso intencional de força física ou de poder, em ameaça ou ato, contra (...) outra pessoa, grupo ou comunidade, que resulte em (...) lesão, morte, agravo psicológico, distúrbios de desenvolvimento ou privação".

Alguns exemplos de violência são: física, verbal, moral, econômica, política, social, conjugal, policial, sexual e organizacional (Rosa; Brito, 2009). A violência, como conceito aceito pelo senso comum, refere-se à agressão física de um indivíduo ou grupo sobre o outro (Rosa; Brito, 2009).

Para Westwood (2003), a violência, em seu sentido amplo (violência contra a pessoa, psique e espírito, representando um mal intencional contra o outro), é inerente à organização. $\mathrm{O}$ autor assume a premissa de que a organização é locus de relações de poder perversas e autoritárias, que submetem alguns indivíduos a constantes humilhações, sarcasmos, difamações, violências verbais, maus-tratos, perseguições, violência contra sua identidade.

Rosa e Brito (2009) acreditam que a violência simbólica tem presença significativa no contexto atual das organizações, uma vez que, ao manipularem elementos simbólicos da organização, seus atores dominantes contribuem para construção de uma comunidade de significados e exercem papel de controle.

Considerando que as dimensões (literal e simbólica) da violência fazem parte da dinâmica das organizações, a abordagem construcionista pode servir de base para desvendar os sentidos atribuídos aos atos gerados por estas dimensões.

\section{Abordagem Sócioconstrucionista: Perspectiva Teórica para Compreensão dos Sentidos da Violência no Trabalho}

O construcionismo, na perspectiva da sociologia do conhecimento, é vinculado a Berger e Luckmann (2004) em A Construção Social da Realidade. Para estes autores, o ser humano é um produto social. Desta forma, a realidade é construída socialmente, moldada por uma dinâmica de conservação e ruptura que possibilita sua ressignificação e a transformação social.

Na perspectiva da psicologia social, o construcionismo é vinculado a Gergen (1985, p.266) que assevera que "a investigação sócio-construcionista preocupa-se, sobretudo, com a explicação dos processos, por meio dos quais as pessoas descrevem, explicam ou dão conta do mundo (incluindo a si mesmos) em que vivem".

Gergen (1985) esclarece que para ter acesso aos sentidos produzidos e às ressignificações socialmente construídas, a abordagem construcionista recorre à noção das práticas discursivas dos sujeitos, ou seja, a linguagem em ação. As narrativas "são elementos importantes na criação de sentidos e dos conteúdos simbólicos, não apenas dos discursos hegemônicos, mas também como formas de emergência de conteúdos simbólicos de resistência e contra-hegemônicos" (Alves; Blikstein, 2006, p. 426). Neste contexto, as reclamações trabalhistas apresentam esse confronto entre opressores e oprimidos, por meio das "teses" da defesa e da acusação, as quais refletem o conflito que ocorre no local de trabalho.

\section{Procedimentos Metodológicos}

Este trabalho pode ser caracterizado como uma investigação qualitativa que, segundo Flick (2009), possui grande relevância para o estudo de relações sociais, permitindo incorporar as questões dos significados e das intencionalidades dos sujeitos como condições inerentes 
aos atos, às relações e às estruturas sociais (Minayo, 2002).

Para alcançar os objetivos propostos, a técnica de coleta de informações utilizada foi a pesquisa documental. Neste trabalho, optou-se pelo uso de documentos públicos. Os documentos públicos são produtos sociais tornados públicos. Eticamente estão abertos para análise por pertencerem ao espaço público, por terem sido tornados públicos de uma forma que permite a responsabilização (Spink, 2004, p. 136).

Foi escolhido, de forma intencional, um processo trabalhista envolvendo o tema violência no trabalho. Durante a fase de seleção do processo a ser escolhido, empregou-se o critério de preferência por casos (sentenças) já transitados em julgado (não cabendo mais nenhum recurso) e, por questões de acessibilidade, os casos ocorridos nas varas do trabalho das cidades de Varginha, Lavras e Três Corações, localizadas no sul de Minas Gerais, por meio de buscas no site do Tribunal Regional do Trabalho de Minas Gerais e consultas (por meio de petição judicial) nas Varas do Trabalho selecionadas.

Como objeto de estudo deste trabalho, foi selecionado um processo que se refere a uma trabalhadora demitida do setor bancário, com litígios trabalhistas e pedidos de indenização por danos morais, para reparação pecuniária dos maus-tratos e humilhações, ocorridos no espaço do trabalho, durante a vigência da relação contratual.

Como plano de análise e interpretação de dados, adotou-se a análise de narrativas. As narrativas, que são criações humanas resultantes de suas interações sociais historicamente construídas, têm a função de constituir os sistemas imaginários e simbólicos de uma sociedade (Berger; Luckmann, 2004). Desse modo, as narrativas são meios para se estudar organizações por meio do estudo de histórias (Imasato, 2005; Schreider, 2009).

Sendo o objeto de análise deste estudo as narrativas processuais registradas pelo processo trabalhista em foco e ressaltando que é composto (dentre outros elementos) por depoimentos em juízo - que tendem a limitar as respostas dos envolvidos no processo trabalhista às perguntas realizadas e a pesquisadora não esteve presente durante as audiências, optou-se por utilizar a técnica em que a autora deste estudo trabalha como narradora dos fatos retratados pelo processo em questão (Imasato, 2005).

A descrição e interpretação das narrativas contidas no processo seguiu protocolo de análise que adotou o seguinte percurso metodológico. Na primeira fase, procurou-se construir uma descrição sintética das especificidades do processo trabalhista, destacando as experiências de violência vividas pela reclamante. $\mathrm{Na}$ segunda fase, foram selecionados extratos das narrativas que expressavam as "vozes" e interpretações dos atores envolvidos no processo, sobre os atos de violência retratados pelo processo trabalhista. Para fins deste trabalho, considerou-se como atores do processo a trabalhadora (reclamante nominada de modo fictício de Maria) e seu advogado de defesa, o juiz do trabalho que julgava o processo e o advogado que representava os interesses do Banco $\mathrm{H}$, considerado no processo como reclamado. Na terceira fase do processo de análise, as narrativas registradas no processo foram agrupadas em três categorias de análise que abrigam as produções discursivas dos atores, ou seja, Acusação, Defesa e Juiz do trabalho. Finalmente, foram identificadas diferentes subcategorias de análise que pudessem revelar os sentidos da violência sob a ótica dos atores acima mencionados.

Optou-se por destacar em itálicos as principais palavras e expressões contidas nas produções discursivas, a fim de identificar sua relação com a categoria /subcategoria analisada.

\section{Análise do Processo}

\section{Descrevendo a História de Maria: Um Caso de Violência e Perdas}

Maria foi admitida em um banco privado brasileiro em novembro de 2001 e demitida sem justa causa em novembro de 2008, em Varginha, cidade no Sul de Minas Gerais. Durante os sete anos em que trabalhou no referido banco (Banco H), Maria alega que sempre desempenhou suas funções com dedicação e rigor. Após ser demitida, Maria, em outubro de 2010, interpôs uma reclamação trabalhista contra o banco onde trabalhou.

A reclamante (Maria) alega que, a partir de 2003, foi submetida a diversas situações vexatórias, exposta ao ridículo e constrangida pelo seu superior hierárquico. O mesmo fixava metas de vendas de produtos (planos de capitalização, seguros de vida etc.) semanalmente, denominando essa campanha de "Super Star" e "Super Mico Estrela". Aqueles funcionários que conseguissem atingir as metas eram obrigados a expor em suas mesas um boneco de pelúcia na forma de um Leão, e, os funcionários, incluindo Maria, que não atingissem uma produção de pelo menos $80 \%$ dessas metas, eram penalizados e recebiam um mico de pelúcia.

O superior hierárquico de Maria expunha a funcionária e os demais subordinados em uma tabela que era exposta na agência aos funcionários e aos clientes, contendo a relação dos "Contemplados pelo Troféu Super Star" e "Contemplados pelo Troféu Mico Estrela".

O funcionário, inclusive Maria, ao receber este "Troféu Mico", era obrigado a mantê-lo em sua mesa de trabalho durante todo o expediente bancário, inclusive carregando-o para onde quer fosse, dentro da agência bancária, perante clientes e funcionários. Ademais, quando a reclamante não atingia as metas estipuladas, era ofendida de forma caluniosa 
pelo superior hierárquico, inclusive com palavras de baixo calão como "incompetente", "burra", "ignorante", "do seu jeito na esquina tá cheio", "você é ruim de serviço", entre outras, proferidas na presença de funcionários e clientes do reclamado (banco).

Maria alega também que sofreu danos morais decorrentes de transportes de valores de forma ilícita, ordenados pelo banco (reclamado), uma vez que era constantemente exposta ao risco de morte, medo e angústia, ao efetuar esse transporte de forma irregular e perigosa.

A reclamante (Maria) afirma que a situação vexatória a que foi submetida causou-lhe danos físicos e morais, adquirindo inclusive, doença de fundo emocional que lhe causou a perda da visão do olho esquerdo.

Embora com apenas 33 anos de idade, Maria sustenta que vive de maneira limitada (dependente de terceiros em seu cotidiano) e incapacitada para o trabalho e que o tratamento desumano a que fora submetida deixou marcas de sofrimento e doença em sua vida.

Afirmando que os danos causados pelo banco (reclamado) são irreparáveis e que o sofrimento causado pelo mesmo é difícil de ser concluído, Maria (reclamante) solicitou uma indenização por danos morais no valor de $\mathrm{R} \$ 150.000,00$ (cento e cinquenta mil reais).

$\mathrm{O}$ reclamado (Banco $\mathrm{H}$ ), representado por seu advogado, negou integralmente todas as acusações feitas pela reclamante (Maria).

O Juiz da Vara do Trabalho onde foi julgada a presente ação trabalhista, após ouvir o depoimento pessoal da reclamante, o depoimento da testemunha da reclamante e analisar as peças da defesa e acusação e provas dos autos do processo, reconheceu o direito da reclamante ao pleito de indenização por danos morais - ofensas e punição vexatória e transporte de valores - no valor de $\mathrm{R} \$ 150.000,00$ (cento e cinquenta mil) reais.

O Banco H (Reclamado), ao "perder" a ação junto à Vara do Trabalho, interpôs um recurso ordinário junto ao Tribunal Regional do Trabalho da $3^{\mathrm{a}}$ Região, solicitando redução no valor da indenização a ser pago à Reclamante (Maria).

O Tribunal Regional do Trabalho da $3^{\text {a }}$ Região, a partir da análise das mesmas peças de acusação e defesa julgadas na Vara do Trabalho e do fundamento da sentença do Juiz titular da referida Vara do Trabalho, julgou o presente processo, reconhecendo o direito da reclamante ao pleito de indenização por danos morais - ofensas e punição vexatória e transporte de valores, porém, reduzindo o valor da condenação para $\mathrm{R} \$ 60.000,00$ (sessenta mil reais). Maria aceitou a sentença proferida pelo referido Tribunal e o Banco H também. Não havendo recurso entre as partes o processo foi transitado em julgado.

\section{Tipificações das Diferentes Formas de Manifestação da Violência no Trabalho}

O caso descrito acima permite retratar diferentes tipificações de formas de manifestação de violência, tais como violência psicológica/psíquica, violência moral e violência simbólica.

A violência psicológica é entendida como qualquer conduta que cause dano emocional e diminuição da autoestima ou que prejudique e perturbe o pleno desenvolvimento ou que vise degradar ou controlar suas ações, comportamentos, crenças e decisões, mediante ameaça, constrangimento, humilhação, manipulação, isolamento, vigilância constante, perseguição contumaz, insulto, chantagem, ridicularização, exploração e limitação do direito de ir e vir ou qualquer outro meio que lhe cause prejuízo à saúde psicológica e à autodeterminação (Lei $\mathrm{n}^{\mathrm{o}}$ 11.430, 2006).

A violência moral também aparece tipificada nesta produção discursiva. De acordo com Cimbalista (2008, p.10), esta forma de violência no ambiente de trabalho "ocorre quando trabalhadores são expostos a situações humilhantes e constrangedoras, repetitivas e prolongadas, durante a jornada de trabalho e no exercício de suas funções".

A violência simbólica pode ser entendida como o "constrangimento estrutural produzido pela ordem simbólica em vigor num determinado espaço de relações" (Rosa, 2007). Transpondo a simbologia dos animais para a nossa sociedade, infere-se que a figura do Leão simboliza "autoridade real, força, coragem, vitória, justiça, sabedoria e proteção" (Pastore, 2009, p. 91). A figura do Mico referese a uma situação embaraçosa, que causa vergonha, vexame (Ferreira, 2010). Deste modo, o superior hierárquico de Maria utilizou um símbolo de demérito/humilhação (Mico) popularmente conhecido como instrumento para exercício da violência, ao obrigá-la a "desfilar" perante colegas de trabalho e clientes carregando aquele boneco de pelúcia.

Ao ser obrigada pelo banco a transitar entre agências sem escolta, portando valores em espécie, o advogado de Maria alega que ela sofreu um medo e uma angústia constantes frente à possibilidade de ocorrência de violência física, entendida como qualquer conduta que ofenda sua integridade ou saúde corporal (Lei $\left.{ }^{\circ} 11.430,2006\right)$.

A importância em tipificar e enfatizar essas formas de manifestação de violência faz parte do processo de entendimento do sentido atribuído a essas manifestações de violência pelos atores envolvidos no processo tramitado no âmbito da justiça do trabalho.

\section{Os Sentidos da Violência para os Atores Envolvidos no Processo Trabalhista}

Neste tópico serão apresentados os sentidos atribuídos 
às manifestações de violência pelos atores envolvidos no processo tramitado no âmbito da justiça do trabalho em foco. Os discursos foram agrupados conforme as categorias Acusação, Defesa e Juiz do Trabalho.

\section{Os sentidos da violência para a acusação.}

As análises das produções discursivas da peça de acusação da Reclamante revelam sentidos de humilhação, sofrimento psicológico e adoecimento em relação às manifestações de violência sofridas por Maria em seu ambiente de trabalho.

Alencar e La Taille (2007, pp.218-220) definem humilhação como um "rebaixamento moral", cuja prática, mais grave no caso da humilhação pública, é nefasta ao equilíbrio psicológico do indivíduo, causando ao mesmo "sentimento de vergonha e abalo na estrutura afetiva (timidez, revolta, imunidade a críticas alheias etc.)", podendo "destruir o autorrespeito".

Acredita-se que a manifestação da violência retratada nas falas e comportamento do superior hierárquico de Maria corresponde a uma abordagem da ciência social que trata a violência como resposta, como uma reação comportamental do autor frente a sua frustração em relação a uma situação desfavorável (Wieviorka, 2003). Para esta abordagem, a violência pode conter aspectos que sugerem uma lógica de perda de sentido, uma vez que seu autor vem exprimir um sentido perdido, em que a violência parece substituir, pura e simplesmente, o que significa que está ausente, ou de alguma forma defeituoso (Wieviorka, 2003, 2006).“A violência é uma conduta de crise, uma resposta a mudanças na situação do ator ou dos atores, que reage $(\mathrm{m})$ principalmente pela frustração" (Wieviorka, 2006, p. 1151). Gaulejac (2007) complementa esta perspectiva ao afirmar que, embora as organizações não sejam neuróticas, perversas ou paranoicas, seus modelos de gestão podem provocar situações em que seus empregados desenvolvam comportamentos neuróticos, perversos ou paranoicos.

Para Dejours (2006), o sofrimento no trabalho gera uma série de manifestações psicopatológicas e descompensações psicopatológicas (rupturas do equilíbrio psíquico) no trabalhador. $\mathrm{O}$ estresse e o adoecimento físico e mental são considerados efeitos adversos do trabalho à saúde do trabalhador (Krug, 2006).

Os trabalhos de Silva, Pinheiro e Sakurai (2007)e Finazzi Santos (2009) são adequados para ilustrar o sofrimento no trabalho no setor bancário. O primeiro evidenciou altas taxas de afastamento bancário para tratamentos médicos em primeiro lugar por doenças osteomusculares e em segundo para transtornos mentais. O segundo trabalho obteve resultados semelhantes, constatando-se que, no período de 1996 a 2005, houve 181 suicídios de trabalhadores do setor financeiro, com uma estimativa de uma tentativa diária. Esses dados remeterem-se as afirmações de Dejours (2004) e Seligmann-Silva (2007) ao discorrem sobre a elevada incidência de diversos transtornos mentais referentes ao trabalho, como a depressão, alcoolismo, síndrome do esgotamento profissional (burnout), bem como a taxa elevada de suicídios.

Nesse sentido, essas reflexões levam a concluir que a reclamante conviveu e suportou, durante vários anos, todos estes sofrimentos vividos, por ter medo. Medo da ameaça constante de demissão gera condutas de obediência e submissão (Dejours, 2006). As organizações criam um círculo vicioso explorando o sofrimento dos funcionários frente à precarização do trabalho e iminência constante de demissão. Por meio da gestão do medo, sustentam sua autoridade e, ameaçando-os, buscam estimular a produtividade (Dejours, 1992). Maria é o retrato desta questão cada vez mais recorrente e desta dinâmica organizacional ultrajante envolvendo sofrimento e adoecimento no trabalho.

\section{Os sentidos da violência para a defesa.}

Analisando as produções discursivas (advogados) da peça da defesa do Reclamado (Banco H) em relação à alegação de Maria, verificou-se que a instituição negou todos os fatos descritos na peça de acusação. Neste trabalho, parte-se do pressuposto de que, negando que as relações de trabalho (gerenciais) eram desumanas, antiéticas ou hostis, os advogados do Banco $\mathrm{H}$ buscaram criar um cenário laboral equilibrado para então introduzirem seu argumento de defesa quanto às acusações feitas pela Reclamante: a naturalização da violência, a violência como algo sem sentido.

Ressalte-se que, no mundo atual de grande competitividade, é normal e (...) natural que haja cobrança por parte de seus superiores hierárquicos como críticas construtivas, cobranças e avaliações sobre o trabalho executado. (...) E tal cobrança se reflete de maneira positiva, como uma forma de incentivar a equipe de trabalho para que busquem melhores resultados, não constituem assédio moral. (Relato da peça da defesa)

Esta produção discursiva traz à tona o sentido de naturalização do processo de violência sofrido por Maria, por meio de uma dissimulação discursiva (Faria; Meneghetti, 2011), que trata esta mesma violência como uma forma de incentivo da equipe por melhores resultados. A racionalidade econômica se torna um dispositivo eficaz para banalizar e naturalizar o sentido da violência.

$\mathrm{O}$ Banco $\mathrm{H}$ naturaliza a violência sofrida por Maria e a descreve como algo sem sentido, como se não fizesse sentido tratar esse processo como violência. "É como se a violência se encontrasse esvaziada de qualquer sentido (...) porque caiu na banalidade pelo efeito de dessimbolização" 
(Pereira, 2010, p. 99). É a desdramatização do mal. A violência então não se constituiria como violência em si, e sim como algo inerente ao mundo corporativo e socialmente justificado e legitimado. As situações de violência descritas por Maria não são tratadas como violência, mas como situações normais onde às práticas de gestão aplicadas são coerentes com o mundo de alta competitividade em que está inserido.

\section{Os sentidos da violência para o juiz do trabalho.}

As análises das produções discursivas constantes do veredito do juiz do trabalho denotam sentidos atribuídos à violência que se contrapõem à tese da defesa, ou seja, reprovação da naturalização/banalização da violência sofrida pela reclamante. Este sentido gera outro sentido, o de inibição/combate das manifestações de violência praticadas pelo Banco $\mathrm{H}$, por meio de medidas pedagógicas e punitivas infligidas à instituição.

Em casos como o analisado nesta demanda, cujas agressões são absurdas e graves, o reclamado deve sofrer punição que lhe motive a tomar precauções dentro do seu ambiente de trabalho (...). A busca deve ser pela inibição deste tipo de conduta e não de simples reparação. (Fundamento do juiz do trabalho)

Acredita-se que o juiz do trabalho concorde que esta banalização do mal (da violência) trata de um processo que implica responsabilidades, que pode ser "interrompido, controlado, contrabalançado ou dominado por decisões humanas" (Dejours, 2006, p.22). Medidas que humanizem as relações de trabalho e limites éticos das atuações dos administradores a fim de evitar o adoecimento dos trabalhadores devem ser implementados e o combate à violência no local de trabalho deve se basear em uma campanha de tolerância zero (Abualrub; Al-Asmar, 2011; Howard, 2001).

\section{Considerações Finais}

Em conformidade com as análises realizadas ao longo deste trabalho, observou-se que as narrativas contidas no processo tramitado no âmbito da justiça trabalhista, contêm sentidos inerentes aos discursos hegemônicos e contrahegemônicos ao tratar, por meio das peças da acusação e da defesa, conflitos existentes no local de trabalho. Desse modo, este estudo permitiu retratar diferentes sentidos da violência para os distintos atores envolvidos.

Acredita-se ter desvelado, ao longo das análises deste estudo, os diferentes sentidos da violência para os diferentes atores envolvidos no processo trabalhista. Para a acusação, que defende os interesses de Maria, a violência tem uma conotação carregada de múltiplos sentidos, sendo interpretada como humilhação, degradação, sofrimento psíquico e adoecimento. A defesa, que representa e defende os interesses da organização bancária, interpreta a violência como algo inerente ao trabalho, portanto, um fenômeno organizacional que deve ser naturalizado e socialmente aceito pelas pessoas que trabalham. Esses sentidos da violência estão fortemente vinculados à postura e à defesa dos interesses financeiros em jogo, tendo em vista que o processo prevê indenizações compensatórias devido às repercussões da violência na vida de Maria. Para o Juiz, responsável pelo julgamento do processo, a violência no trabalho assume uma conotação de ofensas, agressões psíquicas, assédio moral, padecimento sentimental e desrespeito aos direitos trabalhistas. Portanto, ela deve ser reprovada, inibida e controlada pela organização. Trata-se de sentidos que se contrapõem à tese da defesa, que banaliza e naturaliza a violência no contexto do trabalho.

No âmbito teórico, este trabalho contribui para minimizar a lacuna existente na elaboração de trabalhos que investiguem a violência nas relações de trabalho, em especial as do setor bancário, a partir de narrativas de funcionários e de discursos atribuídos às organizações; bem como com as diversas áreas de estudo da temática: psicologia social, direito e medicina do trabalho. Ademais, como contribuição empírica, entende-se que os resultados aqui apresentados permitem às organizações do setor bancário constatar os impactos debilitantes que práticas abusivas e dissimulações discursivas, envolvendo o processo de gestão de pessoas, podem causar nos trabalhadores submetidos a essas práticas.

\section{Referências}

Abualrub, R. F., \& Al-Asmar, A. H. (2011). Physical violence in the workplace among Jordanian hospital nurses. Journal of Transcultural Nursing, 22(2), 157 -165 .

Alencar, H. M.,\& La Taille, Y. (2007). Humilhação: $\mathrm{O}$ desrespeito no rebaixamento moral. Arquivos Brasileiros de Psicologia,59(2), 217-231.

Almeida, K. N. T., Melo, M. C. O. L., \&Brito, M. J. (2006). Políticas e práticas de gestão de pessoas em organizações intensivas em tecnologia: Um estudo descritivo em provedores de acesso à rede mundial de computadores. Revista Eletrônica de Gestão Organizacional, Recife, 4(1), 21-37.

Alves, M. A., \&Blikstein, I. (2006). Análise da narrativa. In C. K. Godoi, R. Bandeira-de-Mello,\&A. B. Silva (Orgs.),Pequisa qualitativa em estudos organizacionais:Paradigmas, estratégias e métodos 
(pp.403-428). São Paulo: Saraiva.

Amazarray, M. R.(2011). Trabalho bancário contemporâneo: Cotidiano laboral marcado por práticas de violência psicológica e assédio moral. InJ. A.Netz,\&P. A. B. Oliveira (Orgs.),Teatro de sombras:Relatório da violência no trabalho e apropriação da saúde dos bancários(pp. 98-118). Porto Alegre:SindBancários Publicações.

Berger, P. L.,\&Luckmann, T. (2004).A construção social da realidade:Um livro sobre a sociologia do conhecimento. Lisboa: Dinalivros.

Bessi, V. G. (2009). Modos de expressão da resistência no cotidiano do trabalho bancário.Tese de Doutorado, Universidade Federal do Rio Grande do Sul.Recuperado dehttp://www.lume.ufrgs.br/ handle/10183/17415?locale=en em 08/12/2012.

Cimbalista, S. (2008). O custo da violência moral no trabalho. Análise Conjuntural,30(03-04), 10-12.

Dejours, C. (1992). A loucura do trabalho. São Paulo: Cortez.

Dejours, C. (2004). Subjetividade, trabalho e ação. Revista Produção, 14(3), 27-34.

Dejours, C. (2006). A banalização da injustiça social. Rio de Janeiro: Editora FGV.

Faria, J. H., \& Meneghetti, F. K. (2011). Dissimulações discursivas e violência no trabalho. In J. A. Netz,\&P. A. B. Oliveira(Orgs.),Teatro de sombras: Relatório da violência no trabalho e apropriação da saúde dos bancários (pp.44-58). Porto Alegre: Sind Bancários Publicações.

Ferreira, A. B. H. (2010).Aurélio século XXI: O dicionário da Lingua Portuguesa. Rio de Janeiro: Positivo.

Ferreira, J. B. (2007). Trabalho, sofrimento e patologias sociais:Estudo com trabalhadores bancários e anistiados políticos de uma empresa pública. Dissertação de Mestrado,Universidade de Brasília, Brasília. Recuperado dehttp://repositorio.unb.br/ bitstream/10482/1432/1/Dissert \%20\%20Joao\%20 Batista $\% 20$ Ferreira.pdf?origin $=$ publication_detailem 08/10/2013.

Finazzi Santos, M. A. (2009). Patologia da solidão: $O$ suicídio de bancários no contexto da nova organização do trabalho.Dissertação de Mestrado, Universidade de Brasília, Brasília. Recuperado dehttp:// repositorio.unb.br/bitstream/10482/4266/1/2009 MarceloAugustoFinazziSantos.pdf em 09/03/2013.

Finazzi, M. A., Siqueira, M. V. S., \& Mendes, A. M.(2010). Tentativas de suicídio de bancários no contexto das reestruturações produtivas. Revista de Administração Contemporânea, 14(5), 925-938.

Flick, U.(2009). Introdução à pesquisa qualitativa.Porto Alegre: Artmed.

Gaulejac, V. (2007). Gestão como doença social. São Paulo: Editora Ideias e Letras.

Gergen, K. (1985).The social constructionist movement in modern psychology. American Psychologist, 40(3), 266-27.

Grisci, C. L. I. (2008). Trabalho imaterial, controle rizomático e subjetividade no novo paradigma tecnológico. RAE-eletrônica,7(1),Art. 4,[23 f.]. Recuperado de http://www.lume.ufrgs.br/bitstream/ handle $/ 10183 / 20540 / 000631316$.pdf?sequence $=1$

Grisci, C. L. I.,\&Bessi, V. G. (2004). Modos de trabalhar e de ser na reestruturação do trabalho bancário e constituição do sujeito. Sociologias, 12(2), 160-201.

Guimarães, M. C. (2009). Transformações do trabalho e violência psicológica no serviço público brasileiro.Revista Brasileira de Saúde Ocupacional,34(120),163-171.

Howard, J. L.(2001). Workplace violence in organizations: An exploratorystudy of organizational prevention techniques. Employee Responsibilities and Rights Journal, 13(2), 57-75.

Imasato, T.(2005). O sentido do processo de incubação, do processo de planejamento e do plano de negócios na vivência de novos empresários.Dissertação de Mestrado,Universidade Federal do Rio Grande do Sul. Recuperado de http://www.lume.ufrgs.br/bitstream/ handle/10183/4301/000455060.pdf? sequence $=1 \mathrm{em}$ $06 / 11 / 2012$.

Krug, S. B. F. (2006). Sofrimento no trabalho: A construção social do adoecimento de trabalhadoras da saúde. Tese de Doutorado,Pontifícia Universidade Católica do Rio Grande do Sul.Recuperado de http://btd.unisc.br/Teses/ SuzaneKrug.pdf em 09/03/2013.

Krug, E., Dahlberg, L. L., Mercy, J. A., Zwi, A., \& Lozano, 
R. (Eds.). (2002). World report on violence and health. Geneva: World Health Organization.

Lei $\mathrm{n}^{\circ} 11.430$, de 26 de dezembro de 2006.Altera as Leis $\mathrm{n}^{\text {os }}$ 8.213 , de 24 de julho de 1991 , e 9.796 , de 5 de maio de 1999, aumenta o valor dos benefícios da previdência social; e revoga a Medida Provisória $\mathrm{n}^{\circ} 316$, de 11 de agosto de 2006; dispositivos das Leis $\mathrm{n}^{\mathrm{os}} 8.213$, de 24 de julho de 1991, 8.444, de 20 de julho de 1992, e da Medida Provisória ${ }^{\circ}$ 2.187-13, de 24 de agosto de 2001; e a Lei $\mathrm{n}^{\circ} 10.699$, de 9 de julho de 2003. Recuperado dehttp://www.planalto.gov.br/ccivil 03/ Ato2004-2006/2006/Lei/L11430.htm em 20/12/2012.

Maciel, R. H., Cavalcante, R.,Matos, T. G. R., \&Rodrigues, S. (2007).Auto relato de situações constrangedoras no trabalho e assédio moral nos bancários: Uma fotografia. Psicologia \& Sociedade, 19(2), 117-128.

Minayo, M. C. S. (2002).Pesquisa social:Teoria, método e criatividade. Petrópolis: Vozes.

Oltramari, A. P., Grisci, C. L. I., \& Weber, L.(2011).Carreira e relações familiares: Dilemas de executivos bancários. Revista Mal-Estar e Subjetividade, 11(1), 101-133.

Pastore, P. C. F. (2009). Expressões idiomáticas americanas e brasileiras: Um estudo contrastivo baseado na simbologia animal. Revista Trama, 5(9), 85-98.

Pereira, A. L. S. S. (2010). O sentido de terror da violência contemporânea como produtor da apatia. Dissertação de Mestrado,Universidade Federal do Rio de Janeiro. Recuperado de http://fenix2.ufrj.br:8991/F/3P2TJ QL7RCKL9AMG7HMYE121R4L5TIPFTNQQF 71BMI1K5XI5X4-19544? func=full-set-set\&set number $=579637 \&$ set entry $=000004 \&$ format $=999 \mathrm{em}$ 08/04/2013.

Pereira, M. C., Brito, M. J., Carrieri, A. P., Lima, J. B., \&Cappelle, M. C. A.(2008). A abordagem sócioconstrucionista e a produção de sentidos sobre o desemprego: Um estudo no setor industrial da região metropolitana de Belo Horizonte (RM-BH). Organização \& Sociedade,15(47), 49-69.

Rosa, A. R. (2007). (O) braço forte, (A) mão amiga:Um estudo sobre dominação masculina e violência simbólica na organização militar. Dissertação de Mestrado,Universidade Federal de Lavras. Recuperado de http://scholar.google.com/citations?view_op=view citation \&hl=en\&user $=$ eK 9gFMUAAAAJ\&citati on for view $=\mathrm{eK} 9 \mathrm{gFMUAAAAJ}$ :Y0pCki6q DkC em $08 / 04 / 2013$
Rosa, A. R.,\& Brito, M. J. (2009).Ensaio sobre violência simbólica nas organizações. Organização \& Sociedade,16(51), 629-646.

Rosenfield, C. L.(2004). Autonomia outorgada e apropriação do trabalho. Sociologias, 6(12), 202-227.

Salimon, M. I.,\& Siqueira, M.V.S. (2013). Ideologia gerencialista e subjetividade do trabalhador no terceiro setor. Revista de Administração, 48(4),643-657.

Seligmann-Silva, E. (2007). Psicopatologia no trabalho: Aspectos contemporâneos. In Anais, 2 Congresso Internacional sobre Saúde Mental no Trabalho (pp. 64-98). Goiânia: Cir.

Silva, L. S., Pinheiro, T. M. M., \&Sakurai, E. (2007). Reestruturação produtiva, impactos na saúde mental e sofrimento mental: $\mathrm{O}$ caso de um banco estatal em Minas Gerais, Brasil. Cadernos de Saúde Pública, 23(12), 2949-2958.

Schreider, D. (2009). A subjetividade no processo decisório na área de P\&D: Estudo de caso múltiplo através das narrativas. Tese de Doutorado, Universidade Federal do Rio Grande do Sul. Recuperado de http://www. lume.ufrgs.br/handle/10183/18436?locale=en $\quad \mathrm{em}$ 11/06/2013.

Siqueira, M. V. S. (2009). Gestão de pessoas e discurso organizacional. Curitiba: Juruá.

Spink, P. (2004). Análise de documentos de domínio público. In M. J. Spink (Org.), Práticas discursivas e produção dos sentidos nocotidiano: Aproximações teóricas e metodológicas (pp. 123-152). São Paulo: Cortez.

Westwood, R. (2003). Economies of violence: An autobiographical account. Culture and Organization, 9(4), 275-293.

Wieviorka, M. (2003). Violence and the subject. Thesis Eleven, 73(1), 42-50.

Wieviorka, M.(2006). Violência hoje.Ciência e Saúde Coletiva, 11(supl.),1147-1153. 
Endereço para correspondência:

Christiane Batista de Paulo Lobato

Universidade Federal de Lavras, Departamento de Administração e Economia. Campus da Universidade

Federal de Lavras, Centro. Lavras/MG. CEP: 37.200-000

E-mail: chris_batista@yahoo.com.br

Endereço para correspondência:

Mozar José de Brito

Universidade Federal de Lavras, Departamento de Administração e Economia. Campus da Universidade

Federal de Lavras, Centro. Lavras/MG. CEP: 37.200-000

E-mail: mozarjdb@dae.ufla.br 